INEL-95/0059

\title{
Laboratory Tests Evaluating the University of South Florida Mobile Data Acquisition System, Type 2
}

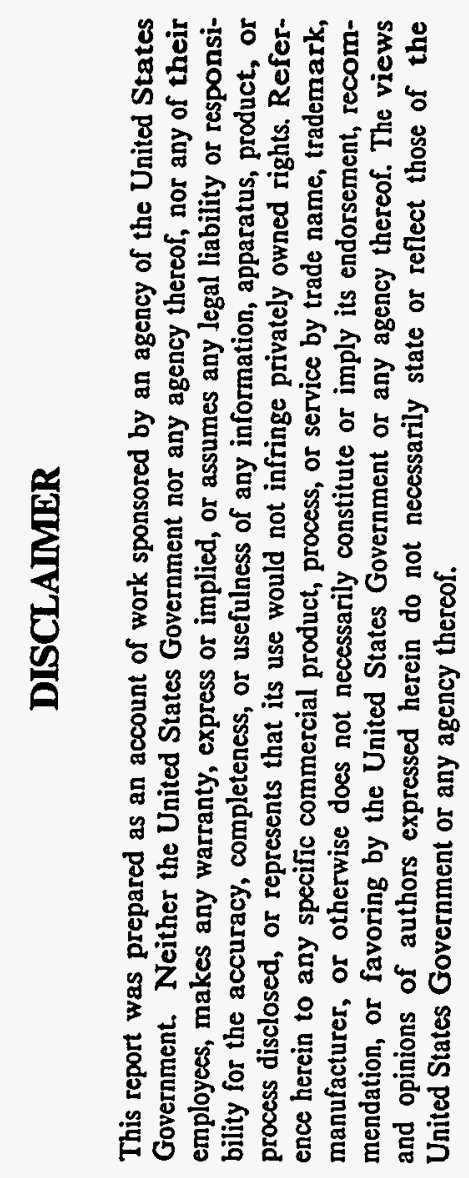

\author{
Dennis M. Kiser \\ Idaho National Engineering Laboratory \\ Curtis Mersman \\ Kansas State University
}

March 1995

Prepared for the

U. S. Department of Energy

Assistant Secretary for Energy Efficiency and Renewable Energy (EE)

Under DOE Idaho Operations Office

Contract DE-AC07-94ID13223 


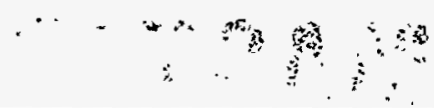




\section{DISCLAIMER}

Portions of this document may be illegible in electronic image products. Images are produced from the best available original document. 


\begin{abstract}
Laboratory tests of the University of South Florida Mobile Data Acquisition System, Version 2, were conducted to evaluate accuracy, susceptibility to temperature changes and vibration, and ease of operation. The collected data were also used to test the MDAS data analysis software package XRD11.EXE. Subject to identified accuracy differences and recommended calibration changes, the system is judged adequate. Confirming in-vehicle tests are planned.
\end{abstract}




\section{ACKNOWLEDGMENTS}

Acknowledgment and special thanks are expressed to the following individuals who assisted in the conduct of these tests:

- $\quad$ R. L. Bottoms, H. E. Knauts, M. E. Martin, of the Idaho National Engineering Laboratory (INEL) Electric and Hybrid Vehicle (EHV) Battery Laboratory.

- P. A. Brookshier, Dana O'Hara, and J. A. Yankeelov, of the Department of Energy (DOE), and G. L. Hunt, G. H. Cole, T. L. Rasmussen, and William E. Kramer, of the INEL EHV Program for their review of the final report.

- $\quad$ Pat Smith for editorial and publication assistance. 


-




\section{CONTENTS}

Abstract $\ldots \ldots \ldots \ldots \ldots \ldots \ldots \ldots \ldots \ldots \ldots \ldots \ldots \ldots \ldots \ldots \ldots$ iii

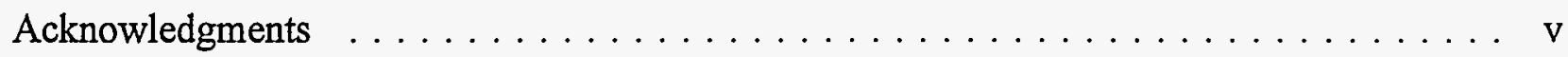

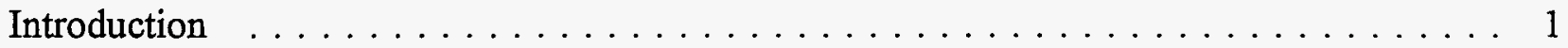

Device Description $\ldots \ldots \ldots \ldots \ldots \ldots \ldots \ldots \ldots \ldots \ldots \ldots \ldots \ldots \ldots \ldots$

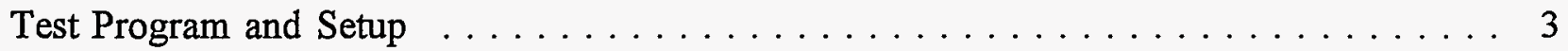

Tests Performed $\ldots \ldots \ldots \ldots \ldots \ldots \ldots \ldots \ldots \ldots \ldots \ldots \ldots \ldots \ldots \ldots \ldots$

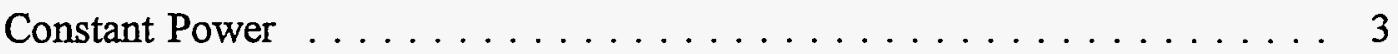

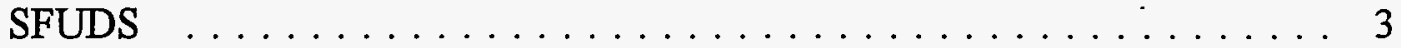

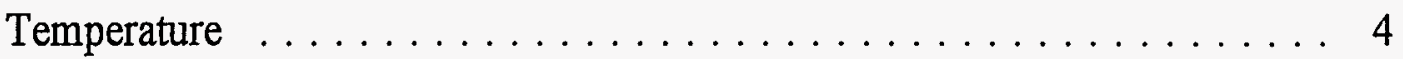

Vibration Table ......................... 4

Battery Laboratory Test Setup and Data Acquisition $\ldots \ldots \ldots \ldots \ldots$

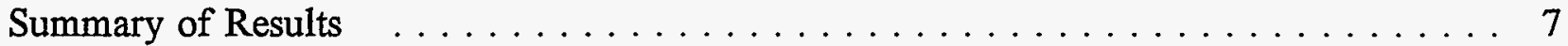

Discussion of Results . . . . . . . . . . . . . . . . . . . 9

Constant Power Tests . . . . . . . . . . . . . . . . . . 9

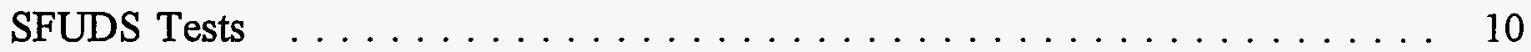

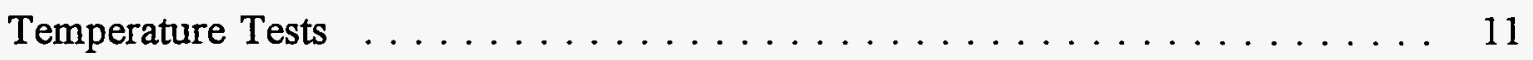

High Temperature $\ldots \ldots \ldots \ldots \ldots \ldots \ldots \ldots \ldots \ldots \ldots \ldots \ldots \ldots$

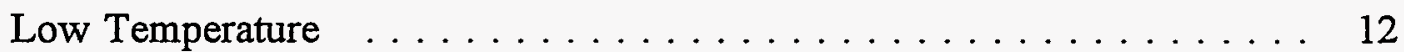

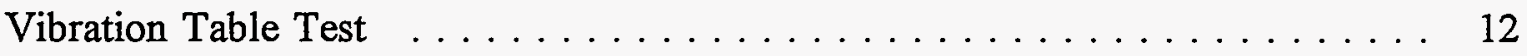

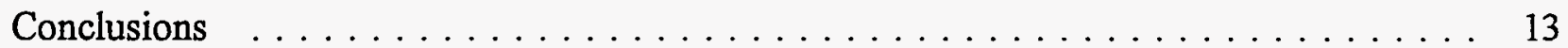

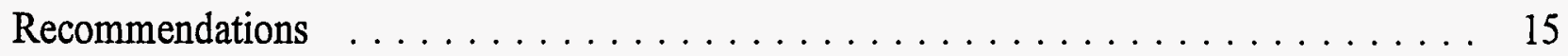

\section{TABLES}

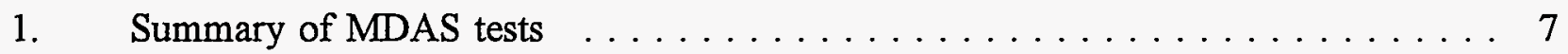

\section{APPENDICES}

A. Test data graphs for each MDAS test $\ldots \ldots \ldots \ldots \ldots \ldots \ldots \ldots$ A-1

B. Detailed description of the MDAS specifications and operation. 


\section{INTRODUCTION}

The University of South Florida Mobile Data Acquisition System (MDAS) is a data acquisition system designed specifically for use in electric vehicles. It provides an essential capability in automated data acquisition to monitor a spectrum of parameters for the vehicle in actual operation. The recorded data are readily downloaded to a database system for evaluation. The tests reported here were conducted at the Idaho National Engineering Battery Laboratory. The items of primary concern were accuracy, susceptibility to field service conditions of vibration and changing temperature, and ease of operation. The Laboratory Data Acquisition System (LDAS) provided the necessary comparison standard, through parallel data input.

\section{Device Description}

The MDAS device is a versatile, compact, self-contained unit that requires very little interaction from the user once it is installed. It requires $12 \mathrm{Vdc}$ for operation. The MDAS is set up to monitor and record data corresponding to battery pack voltage, battery pack current, vehicle speed, battery temperature, cab temperature, and ambient temperature by utilizing its 8-bit A/D converter. Once placed in an EV, the MDAS monitors the vehicle ignition switch and charge door positions to determine when to acquire data.

When the MDAS receives a signal from the ignition switch or charge door of the vehicle, its CPU is turned on and it goes through a boot sequence. The boot sequence tests memory and IO. After the completion of these tests, the MDAS reads the system disk in drive A, thus invoking the Config.sys and Autoexec.bat files. The MDAS then begins collecting data on the channels determined in the operation software. The data is written to extended memory during the test cycle. Upon completion of the cycle, which is determined by the ignition switch being turned off, or by the charge door being closed, the MDAS transfers the data file to the disk in the A drive, and then turns itself off to conserve power. 
The vehicle data stored on the disk can be transferred to another location for permanent storage and analysis. The number of tests that can be stored on the 3.5-in. disk is determined by the sampling rates used and the number of channels recorded.

Voltage, current, and temperature sensors included in the MDAS package, and are calibrated before shipping and are ready to interface the MDAS to the vehicle under test. Besides monitoring the variables mentioned above, the MDAS is equipped to monitor the on/off switches of the vehicle's air conditioning and heating units to indicate when these devices are in operation.

When ordering an MDAS unit, service personnel configure the system software to meet the requirements of the specific vehicle to be tested. The MDAS is then completely ready to acquire data for the user once its sensor leads are in place and the device is powered up. For a more detailed description of the MDAS specifications and operation, see Appendix B. 


\section{TEST PROGRAM AND SETUP}

\section{Tests Performed}

The tests reported herein, performed at the INEL EHV Battery Laboratory, can be divided into four main sections:

1. Constant-power tests

2. SFUDS tests

3. Temperature tests

4. Vibration Table test

During all the tests described, data is collected with both the MDAS and the laboratory data acquisition system (LDAS) and both systems are set to acquire data at the same sample rate in order to provide a direct comparison. The remainder of this section details the various tests listed above.

\section{Constant-Power Tests}

These tests involved connecting both the MDAS and the LDAS to a battery pack in the Battery Laboratory and acquiring data during constant-power discharges of $4 \mathrm{~kW}$ and $5 \mathrm{~kW}$. The purpose of these constant-power tests is to verify the over-all stability and accuracy of the MDAS while the voltage and current change slowly.

\section{SFUDS Tests}

These tests involved acquiring data with both the MDAS and the LDAS during SFUDS cycles of the battery pack. Constant-sample rates for these tests include: $0.5 \mathrm{~Hz}$, $1 \mathrm{~Hz}, 2 \mathrm{~Hz}$, and $10 \mathrm{~Hz}$. The purpose of these tests is to determine the stability and accuracy of the MDAS while the variables being monitored are changing often. 
Temperature Tests

These tests involved acquiring data with both the MDAS and the LDAS during SFUDS cycles of the battery pack at two temperature extremes, $0^{\circ} \mathrm{C}$ and $40^{\circ} \mathrm{C}$. The purpose of these tests was to determine how temperature affects the operation, stability, and accuracy of the MDAS. The temperature tests were performed by placing the MDAS unit, its sensors, the LDAS sensors, and the battery pack in the laboratory environmental chamber while the LDAS unit remained outside the environmental chamber and at room temperature. At both temperatures SFUDS cycles were recorded at sample rates of $0.5 \mathrm{~Hz}, 1 \mathrm{~Hz}$, and $2 \mathrm{~Hz}$.

Because of the poor performance of the battery pack at $0^{\circ} \mathrm{C}$, the SFUDS profile had to be slightly modified. The modifications included removing the regeneration steps and the high power discharge step from the SFUDS profile.

\section{Vibration Table Test}

This test involved acquiring data with both the MDAS and the LDAS during a SFUDS discharge of the battery pack while only the MDAS unit was being vibrated at $0.4 \mathrm{~g}$ and $14.5 \mathrm{~Hz}$. The purpose of this test was to simulate the possible harsh operating conditions of in-vehicle service that the MDAS will be required to withstand, and to determine how the vibration affected the MDAS.

\section{Battery Laboratory Test Setup and Data Acquisition}

MDAS tests 1 through 17 were conducted in the EHV Battery Laboratory, and the battery pack utilized was the Sonnenschein Pack 75C. This battery pack consisted of 11 Sonnenschein $8 \mathrm{G} 24 \mathrm{Gel}$-modules. These modules are $25 \mathrm{~A} \cdot \mathrm{h}$ batteries with a maximum voltage of 14.1 and a minimum voltage of 10.5. For these Battery Lab tests the MDAS instrumentation was connected to Pack $75 \mathrm{C}$ in parallel with the LDAS. The LDAS used in these tests was the LDAS hardware and software. Test 1 was performed with the laboratory 
Normalizer, while the remaining 16 Battery Lab discharges and charges were conducted on the Simulator. In all cases, the same data sampling rate was set for both the MDAS and the LDAS. Once collected, MDAS and LDAS data were compared graphically using Quattro Pro for Windows.

The Normalizer is a battery normalization tester that is used to test electric vehicle battery packs. An IBM PC is used is used for program control and data acquisition. The tester discharges and charges batteries cyclically through programmed sequences of operations. The tester's primary purpose is to provide constant-power discharges of cells, modules, and packs. This unit can handle complex charging algorithms with both constant-voltage and taper steps. The operating ranges are:

- 3 to 300 Vdc Charge Voltage

- 1 to 35 A Charge Current

- 2 to 220 Vdc Discharge Voltage, and

- 10 to 400 A Discharge Current.

The Simulator is a battery tester, governed by an IBM PC for program control and data acquisition, and can be programmed to simulate most road demands on a battery. Its primary purpose is to perform repeated battery discharges using complex discharge profiles, including the effects of regenerative braking, rapid acceleration/deceleration, and rest intervals, that simulate the demands on a battery pack in an electric vehicle. With an extremely fast response time of $1 \mathrm{~s}$, the tester can perform both charge and discharge functions within the ranges of:

- 3 to $300 \mathrm{Vdc}$ Charge Voltage

- 1 to 150 A Charge Current

- 3 to 220 Vdc Discharge Voltage, and,

- 10 to 400 A Discharge Current. 


\section{SUMMARY OF RESULTS}

This section summarizes the test results that describe the performance of the MDAS.

Table 1 summarizes the type of tests run on the MDAS. Each test number represents both a discharge and a charge of the battery pack utilized in the MDAS testing. The sample rate for all the charges of interest was one sample every $30 \mathrm{~s}$, or $0.033 \mathrm{~Hz}$. Ambient temperature in the Battery Test Laboratory was $23^{\circ} \mathrm{C}$.

Table 1. Summary of MDAS Tests

\begin{tabular}{||c|c|c|c||}
\hline Test Number & Discharge Profile & Sample Rate $(\mathrm{Hz})$ & Test Temperature \\
\hline 1 & $4 \mathrm{~kW}$ Constant $\mathrm{P}$ & 0.5 & Room \\
\hline 2 & $5 \mathrm{~kW}$ Constant $\mathrm{P}$ & 0.5 & Room \\
\hline 3 & SFUDS & 10 & Room \\
\hline 4 & SFUDS & 0.5 & Room \\
\hline 5 & SFUDS & 0.5 & Room \\
\hline 6 & SFUDS & 2 & Room \\
\hline 7 & SFUDS & 1 & Room \\
\hline 8 & SFUDS & 2 & $40^{\circ} \mathrm{C}$ \\
\hline 9 & SFUDS & 1 & $40^{\circ} \mathrm{C}$ \\
\hline 10 & SFUDS & 0.5 & $40^{\circ} \mathrm{C}$ \\
\hline 11 & Modified SFUDS & 2 & $0^{\circ} \mathrm{C}$ \\
\hline 12 & Modified SFUDS & 1 & $0^{\circ} \mathrm{C}$ \\
\hline 13 & Modified SFUDS & 0.5 & $0^{\circ} \mathrm{C}$ \\
\hline 14 & SFUDS & 2 & Room \\
\hline 15 & SFUDS & 1 & Room \\
\hline 16 & SFUDS & 0.5 & Room \\
\hline 17 & SFUDS (Vib.) & 2 & Room \\
\hline 18 & & & \\
\hline 19 & & & \\
\hline
\end{tabular}


Graphs of data for each MDAS test are also presented in Appendix A as

Figures

A-1 through A-16. However, because of the similarity of the results, data from all of the tests conducted were not plotted. A complete discussion of the results pertinent to each of the plots is given in the following section.

The various plots were generated by importing data files, from both the MDAS and the LDAS into a spreadsheet and plotting the measured quantities (voltage, current, and temperature) versus time. However, because the MDAS raw data files are in binary form, these files were first converted into ASCII form by running the computer program XRD11.EXE, which was supplied with the MDAS. Once the data were in the spreadsheet, both the MDAS and the LDAS data were aligned on the time axis by shifting the data in time so that the first current measurement that was significantly greater than zero for each of the two systems, overlaid the other. Given that the MDAS and LDAS were programmed to measure the same parameters, and to sample at the same rate, during each test, ideally this should have resulted in the two sets of data matching sample-for-sample in each plot. Using this method to align the data, the time difference between any of the aligned samples can be no more than one sample period.

When illustrating the results of the various SFUDS tests, only at most one cycle of the test has been plotted. This election expands the plot and aids in making a more detailed comparison between the MDAS and the LDAS data. 


\section{DISCUSSION OF RESULTS}

\section{Constant-Power Tests}

The results of the constant-power test (Test 2) are shown in Figures A-1 and A-2. The voltage plots of both the MDAS and LDAS data, in Figure A-1, indicate that the MDAS voltage measurement is approximately $2 \mathrm{~V}$ lower than the corresponding LDAS measurement. Since the MDAS has a $300 \mathrm{~V}$ range, this $2 \mathrm{~V}$ difference represents an uncertainty of less than $1 \%$ of the MDAS voltage range. The voltage difference amounts to a difference in MDAS instrument calibration which can be eliminated by increasing the MDAS voltage scale factor by a factor of 1.008483 .

The data illustrated in Figure A-2 show that the MDAS current measurement is approximately $5 \mathrm{~A}$ lower than the LDAS current measurement. The MDAS has a current range of $-300 \mathrm{~A}$ to $300 \mathrm{~A}$, and therefore this $5 \mathrm{~A}$ discrepancy results in an uncertainty of less than $1 \%$ of the device's full range. The current difference amounts to a difference in MDAS instrument calibration which can be eliminated by increasing the MDAS current scale factor by a factor of 1.103255 .

Some differences between the MDAS and LDAS data are to be expected because of the difference in the resolution of the MDAS compared to the LDAS. Since the MDAS utilizes an 8-bit A/D converter, its resolution is 1 part in 256. Thus, the MDAS $300 \mathrm{~V}$ voltage range, divided into 256 parts, gives a resolution of $1.17 \mathrm{~V} / \mathrm{bit}$. Similarly, the MDAS $600 \mathrm{~A}$ current range yields a resolution of $2.34 \mathrm{~A} / \mathrm{bit}$. The LDAS utilizes a 16-bit A/D converter; its resolution is 1 part in 65;536. Thus, the LDAS 300 voltage range, divided into 65,536 parts, gives a resolution of $5 \mathrm{mV} / \mathrm{bit}$. Similarly, the LDAS 1000 A current range utilizing an internal discharge shunt yields a resolution of $16 \mathrm{~mA} / \mathrm{bit}$. 


\section{SFUDS Tests}

Figures A-3 and A-4 illustrate the results for Test 3, an SFUDS cycle for which the MDAS unit was set to a sampling rate of $10 \mathrm{~Hz}$. This test was performed to verify that the MDAS can record data at high rates during a battery discharge simulating a realistic driving cycle. The plots show that the voltage and current accuracy of the device during this dynamic profile is as good as that displayed during the constant-power tests. Thus, the magnitudes of voltage and current measured can be corrected by increasing the appropriate scale factors as recommended for the constant-power tests. The interesting result of this test is that even though the data sets are aligned, in time, at the beginning of the plots, they drift apart as the number of samples increases. This phenomenon is easily seen in Figures A-3 and A-4. At first thought, this would seem to indicate that the MDAS and the LDAS were not sampling at precisely the same rate, although they were programmed to do so.

To investigate this timing difference further, the number of samples recorded by each data acquisition system are compared between the beginning of the first discharge step of the SFUDS and the end of the last charge step. The MDAS recorded 3,084 samples during this period while the LDAS recorded 3,234. For a sampling interval of $0.1 \mathrm{~s} / \mathrm{sample}$, the MDAS data indicates that this sequence of events took $308.4 \mathrm{~s}$, and the LDAS data indicates that it took $323.4 \mathrm{~s}$. Assuming that the LDAS is the standard of accuracy, then correcting the MDAS sample frequency by taking the time measured by the LDAS, $323.4 \mathrm{~s}$ and dividing by the MDAS's 3,084 samples gives a corrected MDAS sample period of $0.10486 \mathrm{~s}$, a $4.86 \%$ difference (i.e., a factor of 1.0486) from the expected sampling period of $0.1 \mathrm{~s}$.

The following paragraphs show that the sampling rate discrepancy is also samplingrate-dependent.

During Test 14 the sample rate was $2 \mathrm{~Hz}$. Figures A-5 and A-6 display the results of this test. The traces of the MDAS and LDAS data again start together but drift apart as the test progresses. Using the same method as above, the MDAS recorded 641 samples compared to 646 by the LDAS during a $323 \mathrm{~s}$ period. This indicates that the MDAS is recording data 
every $0.50390 \mathrm{~s}$, a $0.78 \%$ difference (i.e., a factor of 1.0078 ) from the expected data acquisition period of $0.5 \mathrm{~s}$

During Test 15, the sample rate was $1 \mathrm{~Hz}$; and during Test 16, the sample rate was $0.5 \mathrm{~Hz}$. Considering Test 15 shown in Figures A-7 and A-8, and Test 16 shown in Figures A-9 and A-10, a difference in sample rate between the MDAS and LDAS is not obvious. Going beyond the plots to the raw data, a slight difference is noticeable. From beginning to end of Test 15 the MDAS recorded 944 samples while the LDAS recorded 948 at a rate of $1 \mathrm{~Hz}$. This results in a $0.42 \%$ difference (i.e., a factor of 1.0042) from the expected data acquisition rate of $1 \mathrm{~Hz}$. Similar results were obtained for Test 16 .

The results of these tests indicate that the accuracy of the sampling rate at which the MDAS records data is frequency-dependent. The faster the MDAS is programmed to record data, the higher the percent error from its expected data acquisition rate. This phenomenon will cause problems if exact time measurements are required, and will introduce error into calculations when utilizing time-dependent data, such as ampere-hour or kilowatt-hour calculations. At low sampling rates of 1 or $2 \mathrm{~Hz}$, these errors would be less significant.

\section{Temperature Tests}

\section{High-Temperature Tests}

Figures A-11 and A-12 illustrate the results of MDAS Test 8. These results are characteristic of the MDAS performance at $40^{\circ} \mathrm{C}$. Comparing Test 8, Figures A-11 and A-12 to Test 14 , Figure A-5 and A- 6 , which is for a similar test at ambient temperature and at a similar sample rate, shows that the high temperature had no noticeable effect on the accuracy or sampling rate of the device. 


\section{Low Temperature Tests}

The results of Test 11 are shown in Figures A-13 and A-14. These graphs indicate how the MDAS performs at $0^{\circ} \mathrm{C}$. Comparing Test 11, Figures A-13 and A-14 to Test 13, Figures A-5 and A-6, which is for a similar test at ambient temperature, and at a similar sampling rate, shows that both the voltage and current recorded by the MDAS, at low temperature, are shifted to values that are high, relative to the voltage and current recorded by the LDAS at room temperature, compared to Figures A-5 and A-6. Comparing Figures A-13 and A-14 to Figure A-4 and A-6 show that the sample rate, however, is not affected by the low temperature. Thus, the MDAS will evidently give a higher reading at low temperatures near $0^{\circ} \mathrm{C}$, or below, than at temperatures of 23 to $40^{\circ} \mathrm{C}$.

\section{Vibration Table Test}

Figures A-15 and A-16 display the results of the vibration table test. These results indicate that subjecting the MDAS to vibration of $0.4 \mathrm{~g}$ at $14.5 \mathrm{~Hz}$ had no effect on its performance. 


\section{CONCLUSIONS}

The tests reported show that the signals measured by the Type 2 MDAS are within the accuracy and precision specified by the manufacturer, Sigma Tec. Systems, Inc. as in Appendix B. However, the MDAS sampling time increment appears to be dependent on the sampling frequency selected, and the MDAS measurements of voltage and current increased at a low temperature $\left(\approx 0^{\circ} \mathrm{C}\right)$. In particular:

- The constant-power tests indicate that both the MDAS voltage and current measurements differed from those of the LDAS. However, these differences were less than $1 \%$ of the MDAS unit voltage and current ranges; and therefore, within specifications for the unit. Both differences can be eliminated by including an appropriate scale factor, of offset, in the MDAS data interpretation software.

- The MDAS sampling rate appears to be dependent on the sampling frequency selected as follows:

- $\quad$ For Test 3, an SFUDS cycle, the MDAS unit was set to a sampling rate of $10 \mathrm{~Hz}$. The MDAS recorded 3,084 samples during the test period, while the LDAS recorded 3,234, which gives a true MDAS sampling period of $0.10486 \mathrm{~s}$, a $4.86 \%$ difference (i.e., a factor of 1.0486 ) from the expected sampling period of $0.1 \mathrm{~s}$.

- $\quad$ During Test 14, the sample rate was $2 \mathrm{~Hz}$. The MDAS recorded 641 samples compared to 646 by the LDAS during a $323 \mathrm{~s}$ period. This indicates that the MDAS is recording data every $0.50390 \mathrm{~s}$, a $0.78 \%$ difference (i.e., a factor of 1.0078) from the expected data acquisition period of $0.5 \mathrm{~s}$. 
- During Test 15 the sample rate was $1 \mathrm{~Hz}$, and during Test 16 the sample rate was $0.5 \mathrm{~Hz}$. From beginning to end of Test 15 the MDAS recorded 944 samples while the LDAS recorded 948 at a rate of $1 \mathrm{~Hz}$. This results in a $0.42 \%$ difference (i.e., a factor of 1.0042) from the expected data acquisition rate of $1 \mathrm{~Hz}$. Similar results were obtained for Test 16.

- Comparing Test 8, Figures A-11 and A-12, which is for the MDAS tested at a temperature of $40^{\circ} \mathrm{C}$ and a sample rate of $2 \mathrm{~Hz}$, to Test 14, Figures $\mathrm{A}-5$ and A-6, which is for a similar test, at ambient temperature, and at a similar sampling rate, comparisons shows that the high temperature had no noticeable effect on the accuracy or sampling rate of the device.

- Comparing Test 11, Figures A-13 and A-14 is compared with Test 14, Figures $A-5$ and $A-6$, which is for a similar test, at ambient temperature, and at a similar sampling rate, show that both the voltage and current recorded by the MDAS at low temperature are shifted to values that are higher, relative to the voltage and current recorded by the LDAS at room temperature. Comparing Figures A-13 and A-14 to Figures A-5 and A-6 shows that the sampling rate, however, is not affected by the low temperature. Thus, the MDAS will evidently give a higher reading at low temperatures (near or below $0^{\circ} \mathrm{C}$ ) than at temperatures of 23 to $40^{\circ} \mathrm{C}$. 


\section{RECOMMENDATIONS}

Based on the tests conducted at the INEL, the second generation MDAS unit, manufactured by Sigma Tec. Systems, Inc., at the University of South Florida, is recommended as a field test data acquisition unit, of reasonable capability, for use in the Department of Energy (DOE) Site Operator Program. The system can be significantly improved if the following three recommendations are implemented:

- If the MDAS scale factors are calculated for instrumentation that is calibrated utilizing a calibrated shunt, as is the INEL LDAS, then differences in measurements taken by the MDAS and LDAS types of systems will be negligible.

- Calculations of the sample period and sample frequency must be reformulated in order to provide sample intervals that are accurate in time. The results of these tests indicate that the accuracy of the sampling rate at which the MDAS records data is frequency-dependent. The faster the MDAS is programmed to record data, the higher the percent error from its expected data acquisition rate. This phenomenon will cause problems if exact time measurements are required, and will introduce error into calculations utilizing time-dependent data, such as ampere-hour or kilowatt-hour calculations. At low sampling rates of 1 or $2 \mathrm{~Hz}$, these errors would be less significant.

- It is unclear whether the MDAS unit itself or the instrumentation was affected by the low temperature of $0^{\circ} \mathrm{C}$. Further testing is needed to isolate these effects. However, it would be wise for users of the MDAS to install the units inside the vehicles, so that the units would be in a warm environment during cold ambient conditions. In order to take advantage of the warming effect of battery or electric motor energy dissipation, it would also be wise to mount the voltage and current sensors inside the vehicle cab, battery pack, or machinery compartments, as opposed to the wheel wells, fender wells, or under-chassis areas that are exposed to the elements. 


\section{APPENDIX A}

Test Data Graphs for Each MDAS Test 


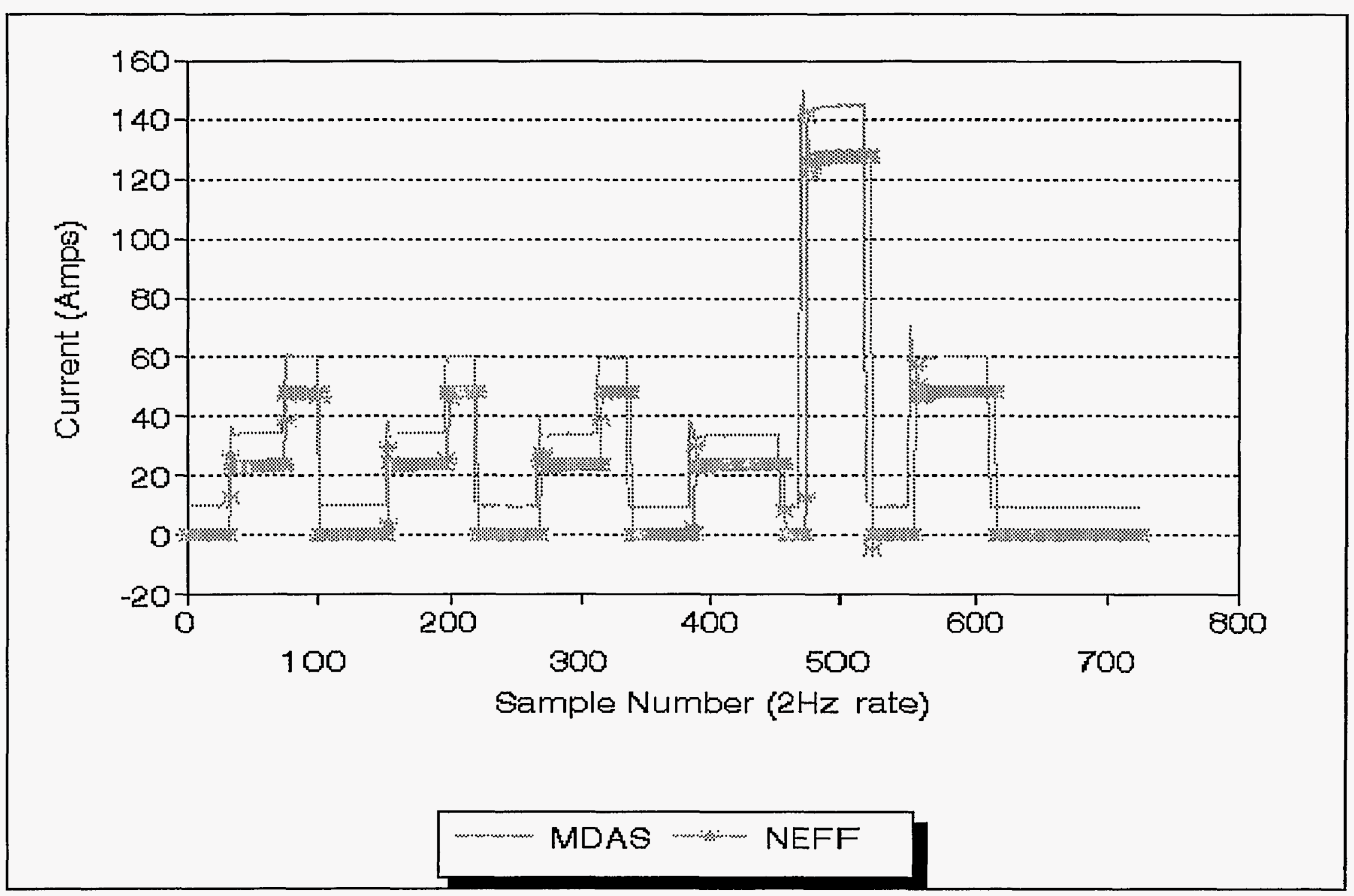

Figure 1. MDAS Test 2 [voltage] $5 \mathrm{~kW}$ constant power discharge. 


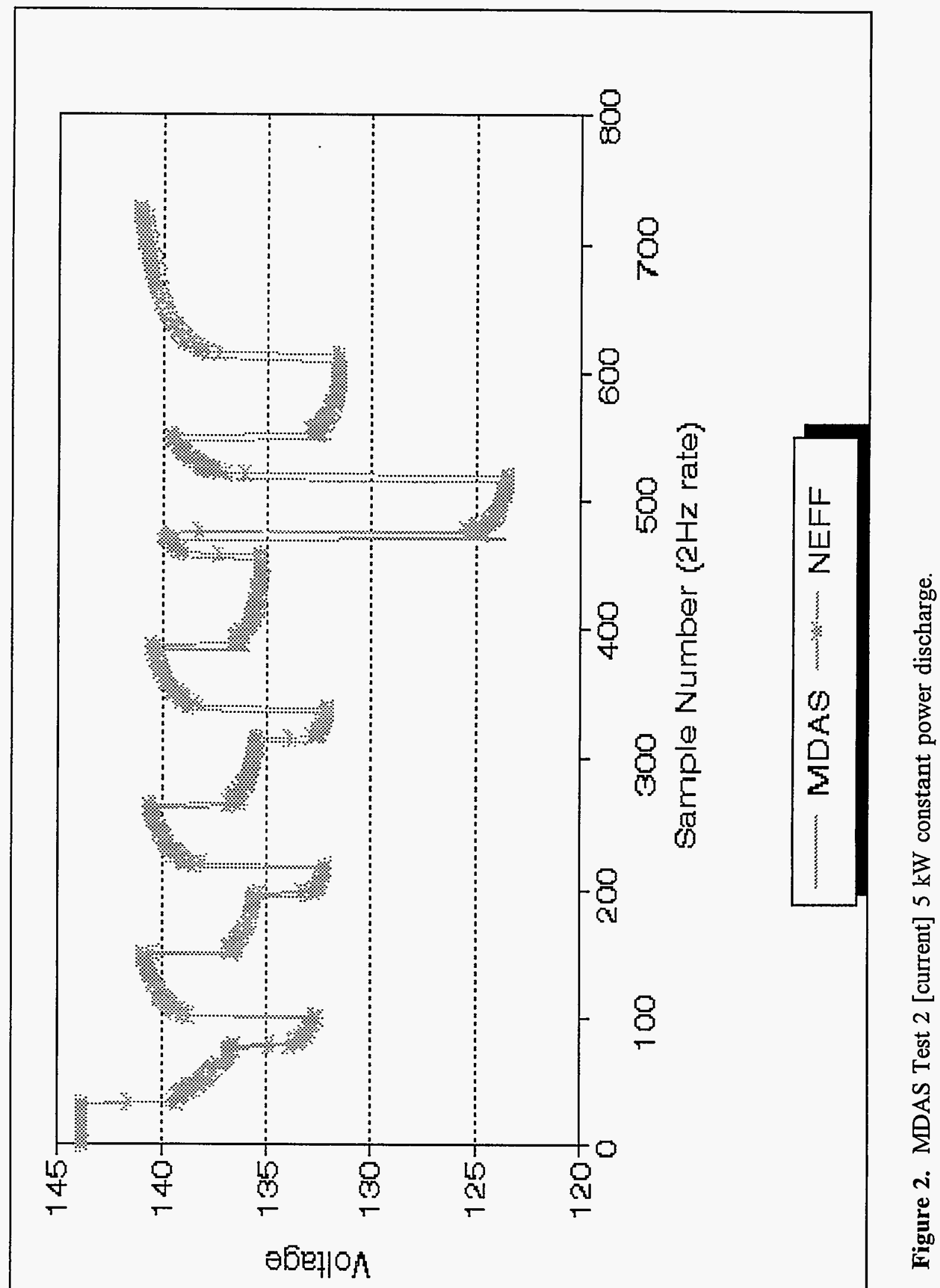




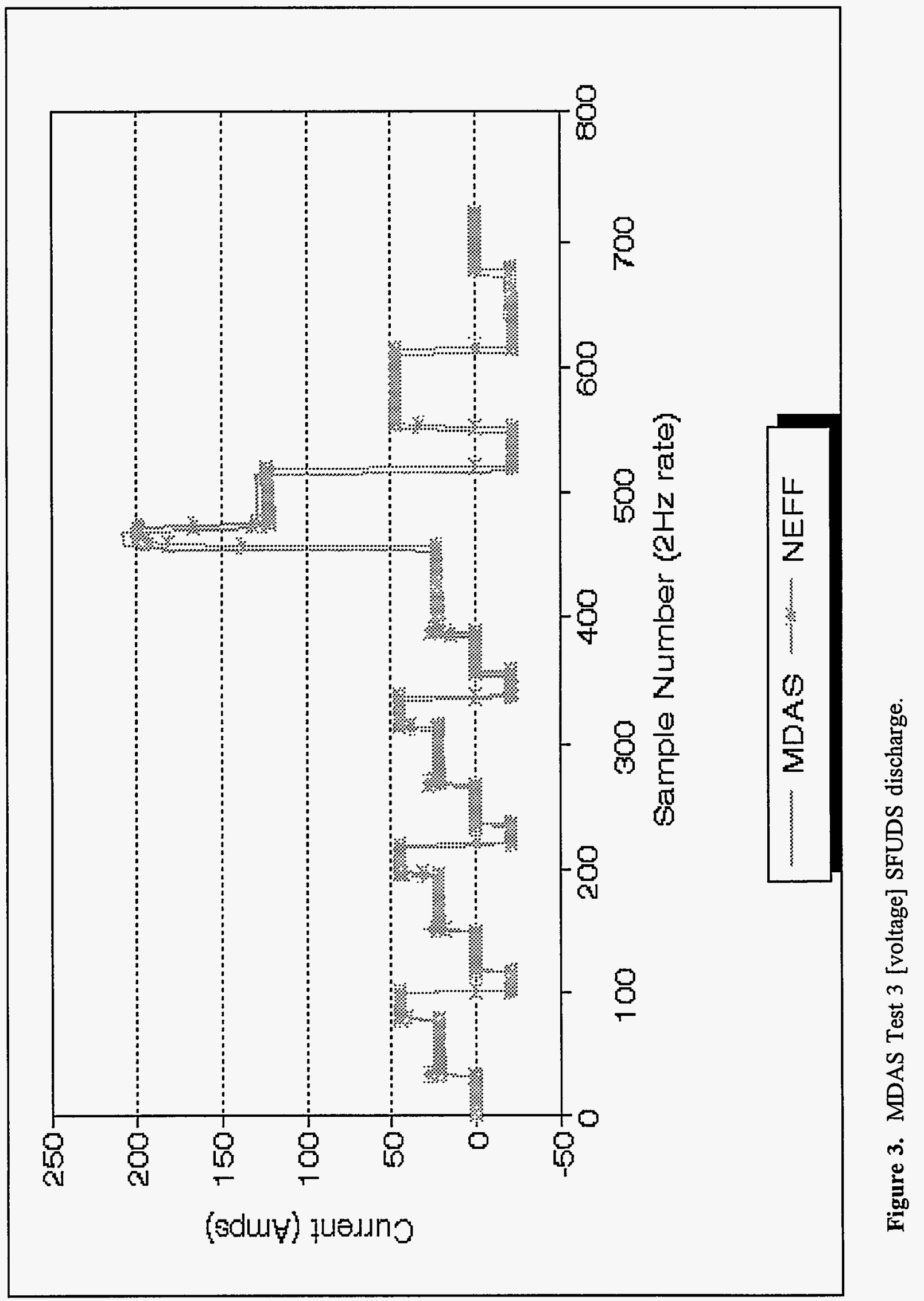




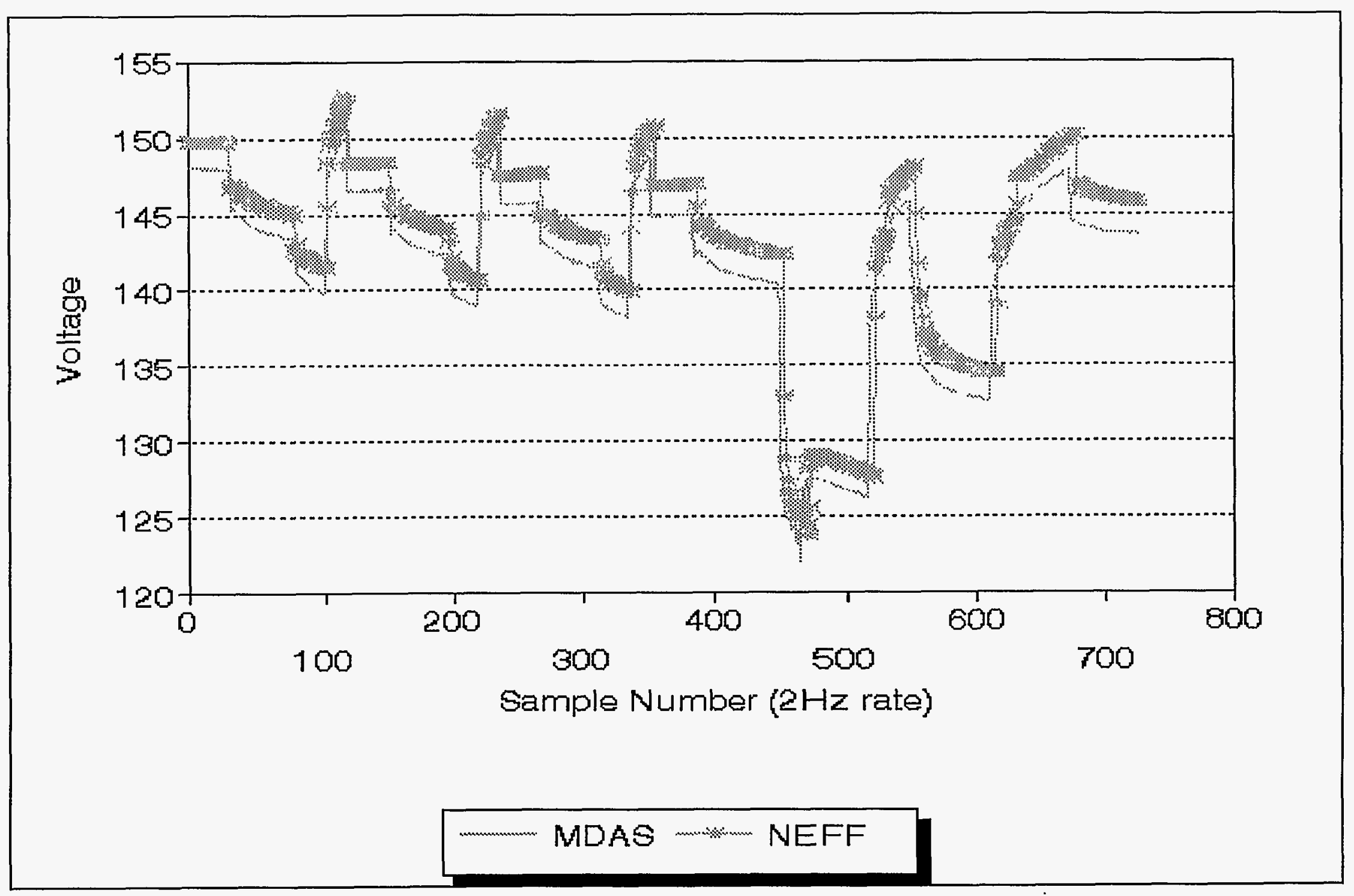

Figure 4. MDAS Test 3 [current] SFUDS discharge. 


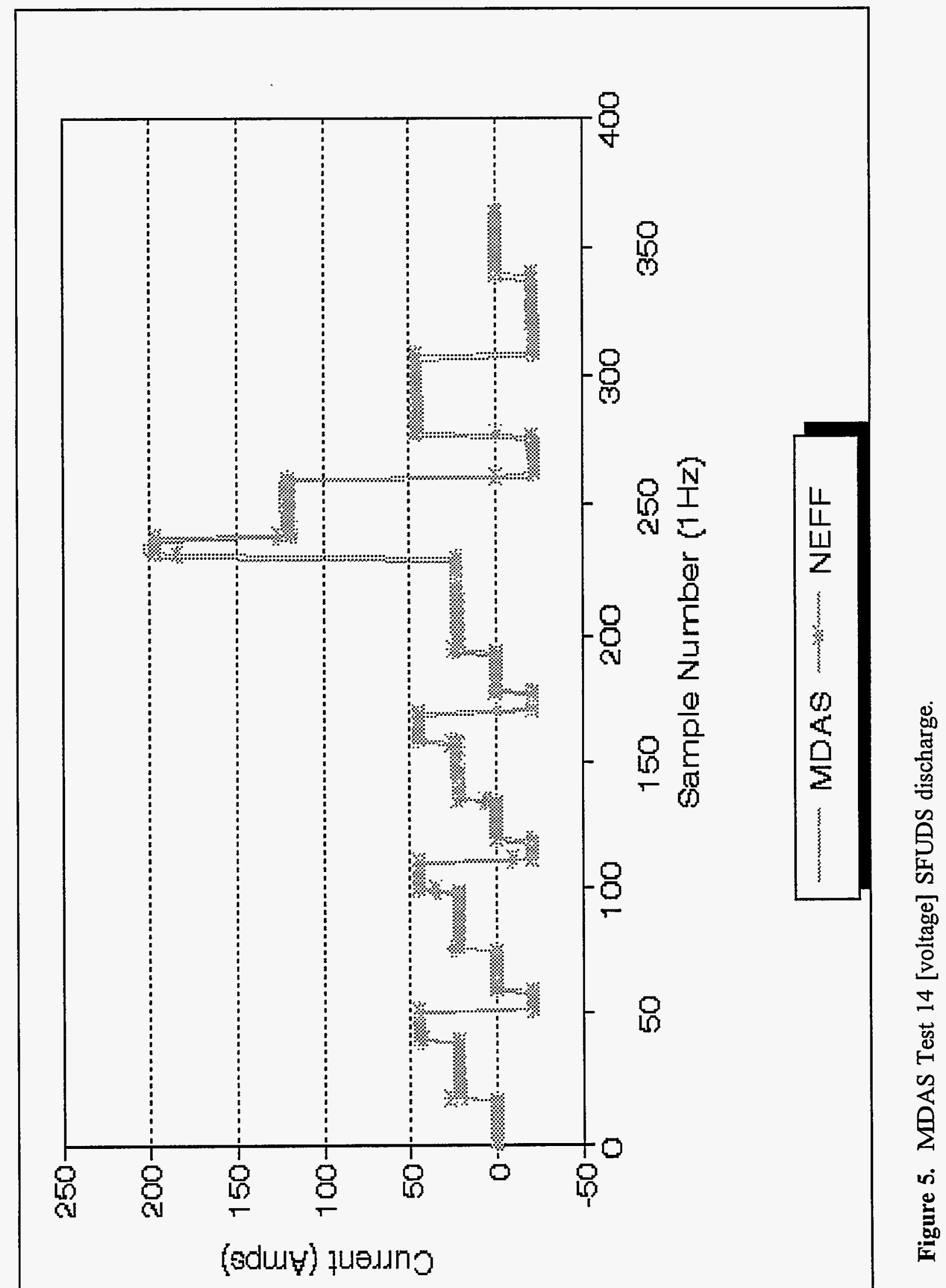




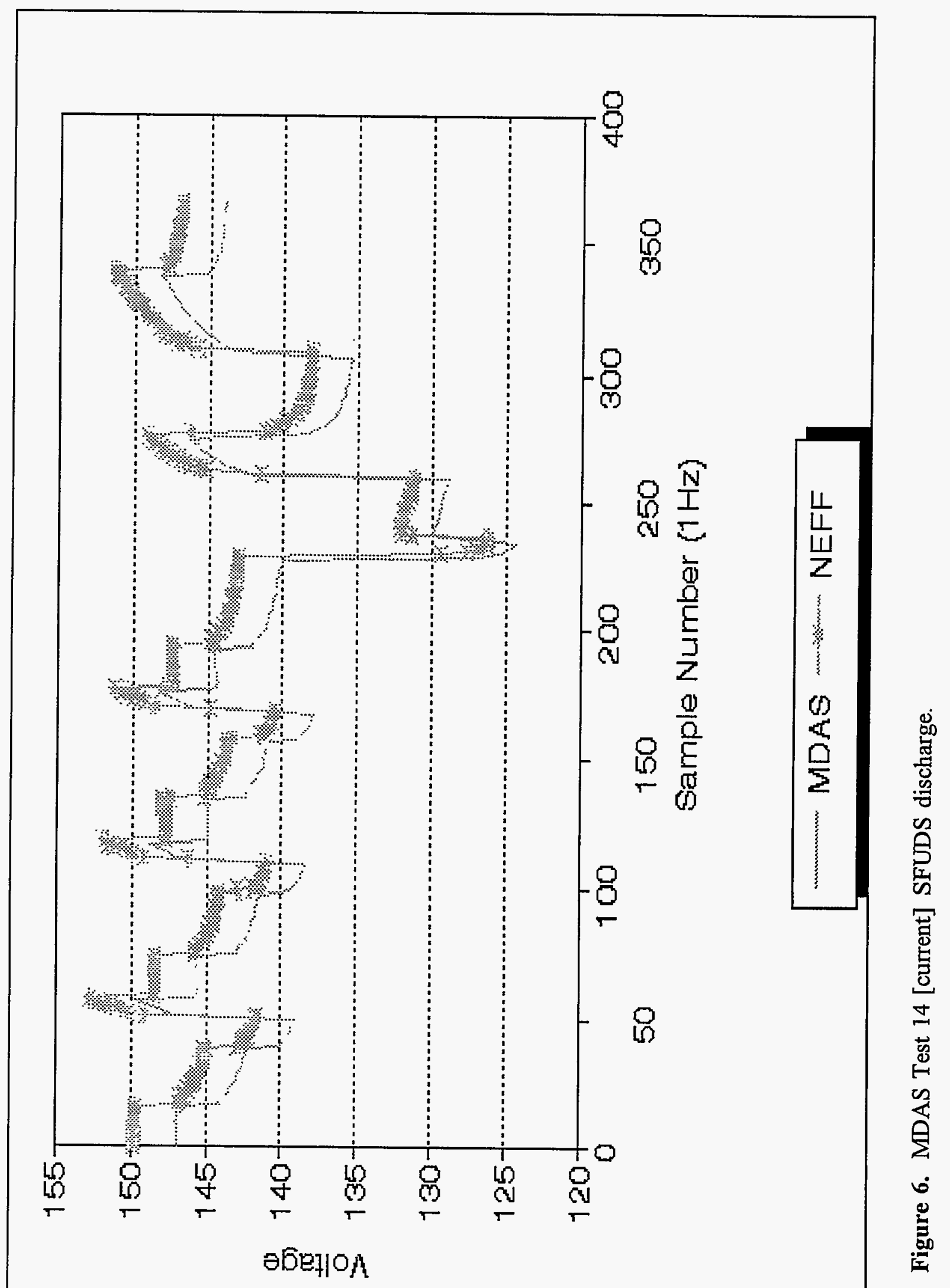




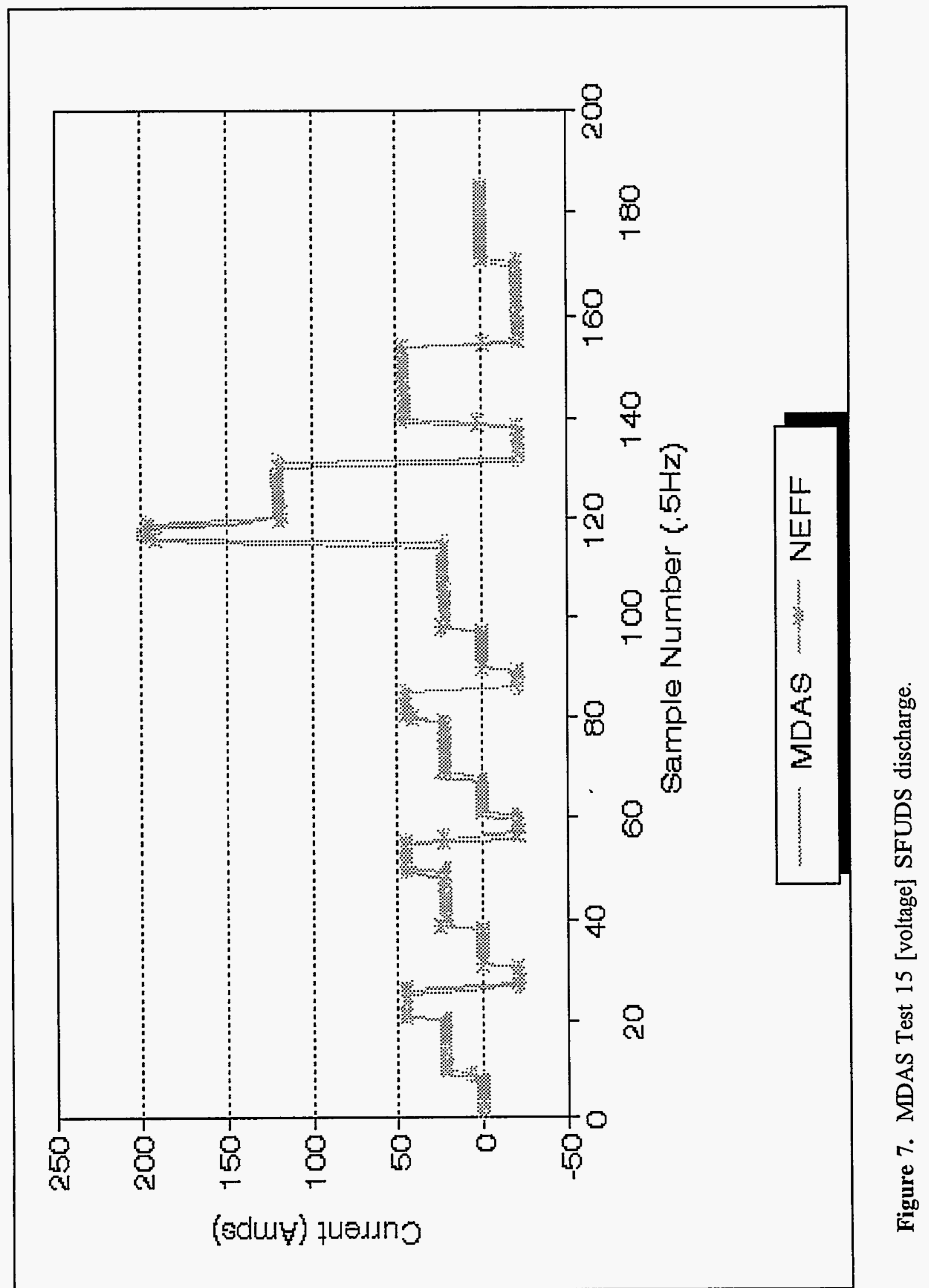




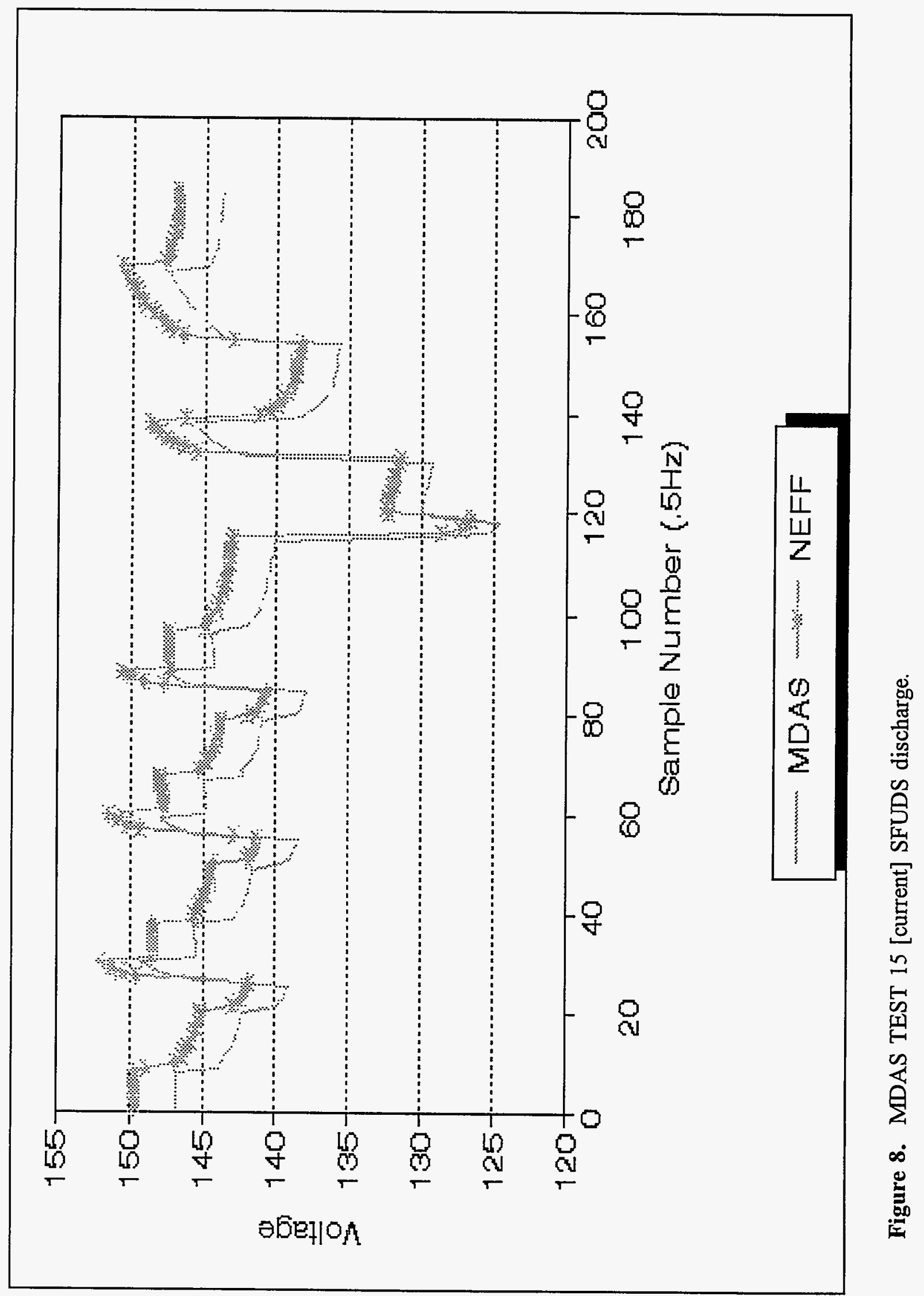




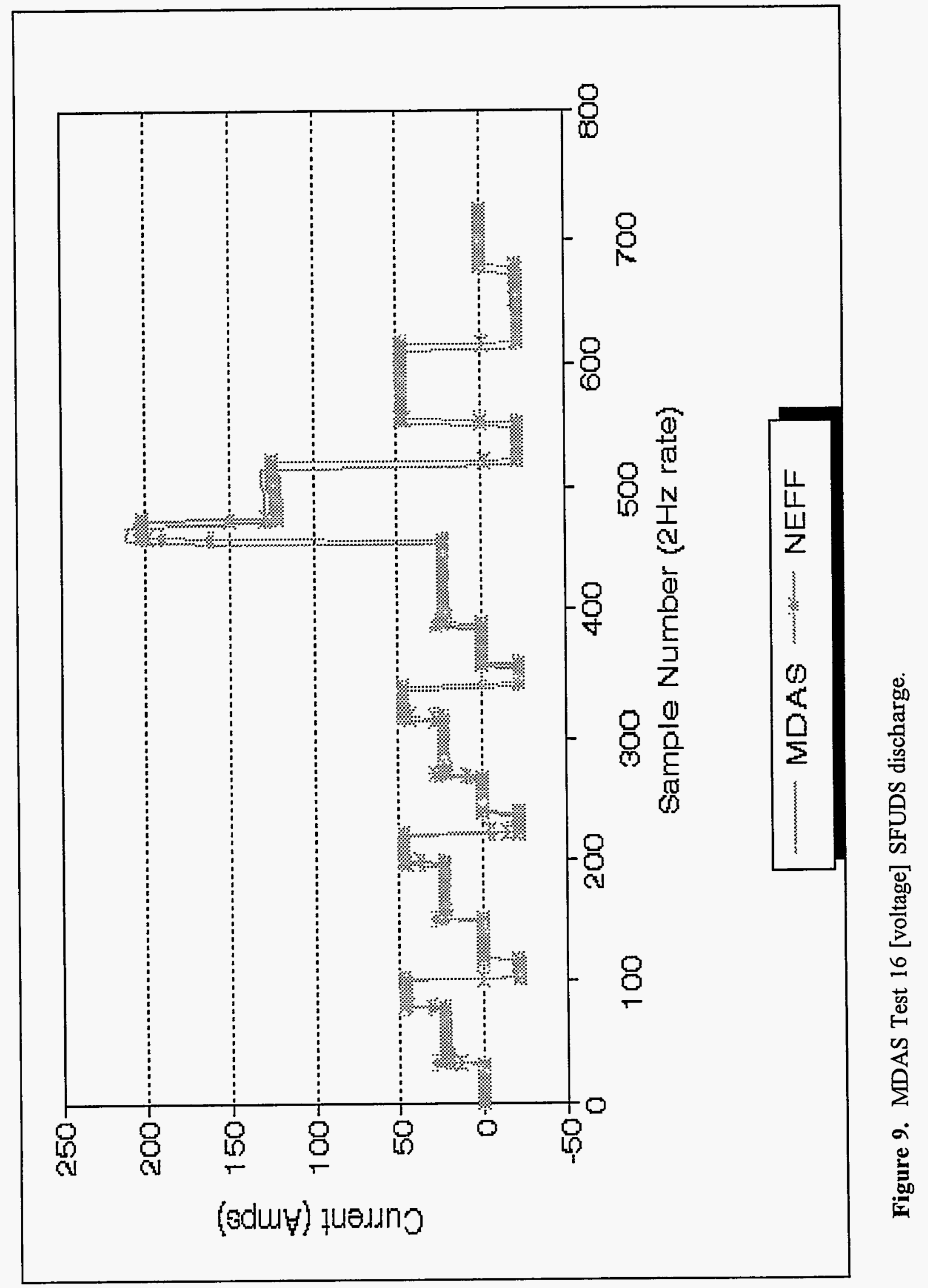




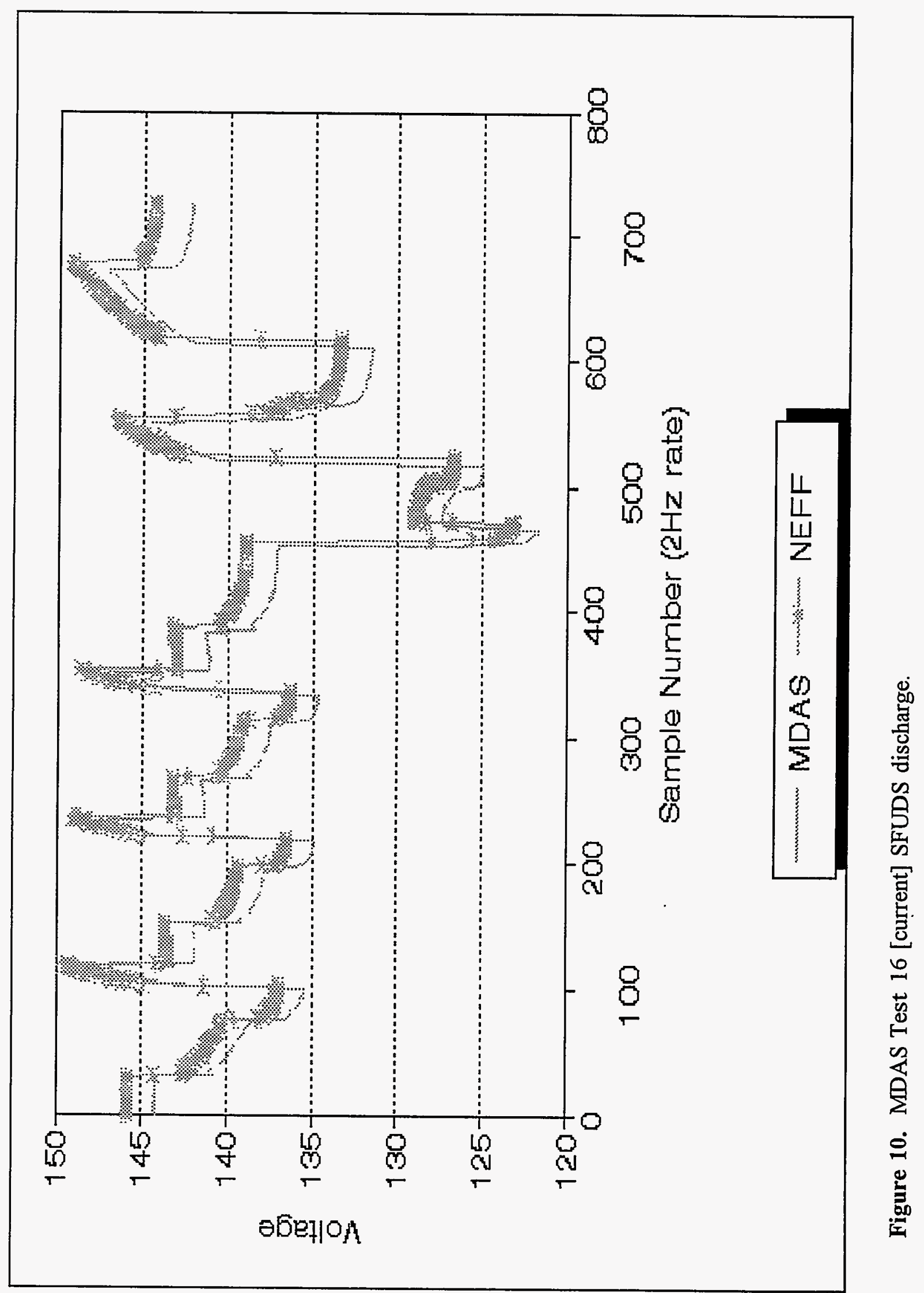




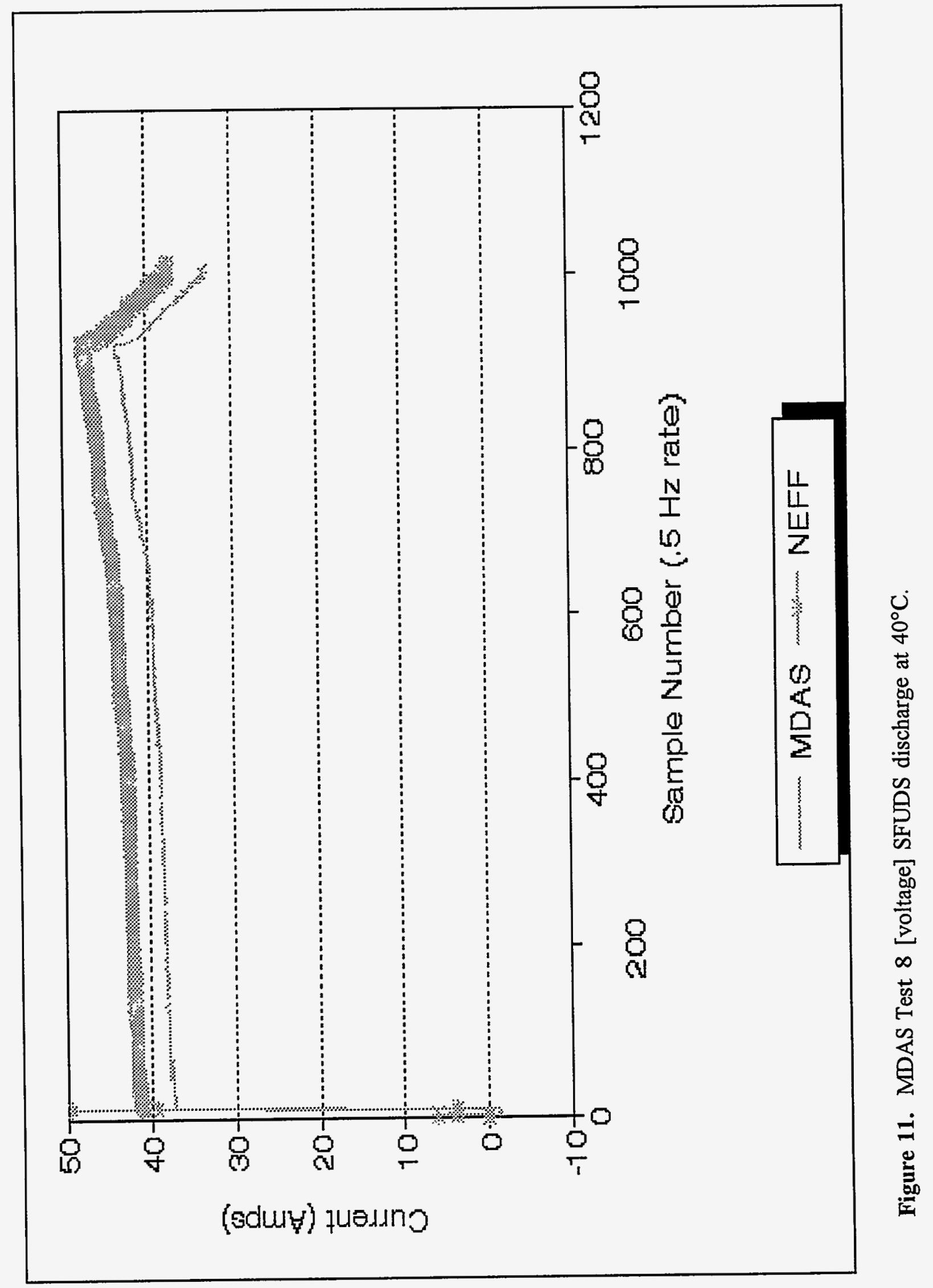




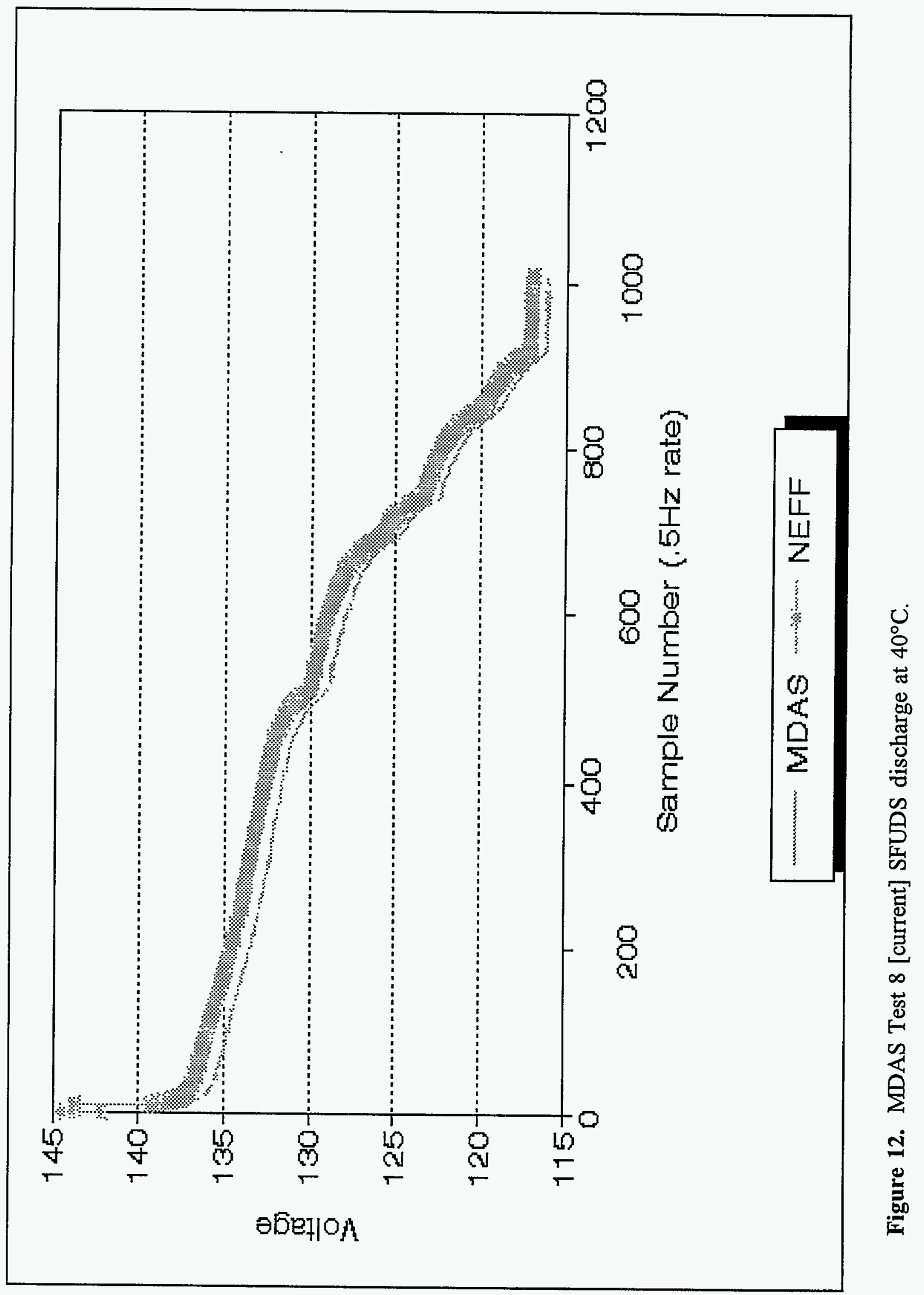




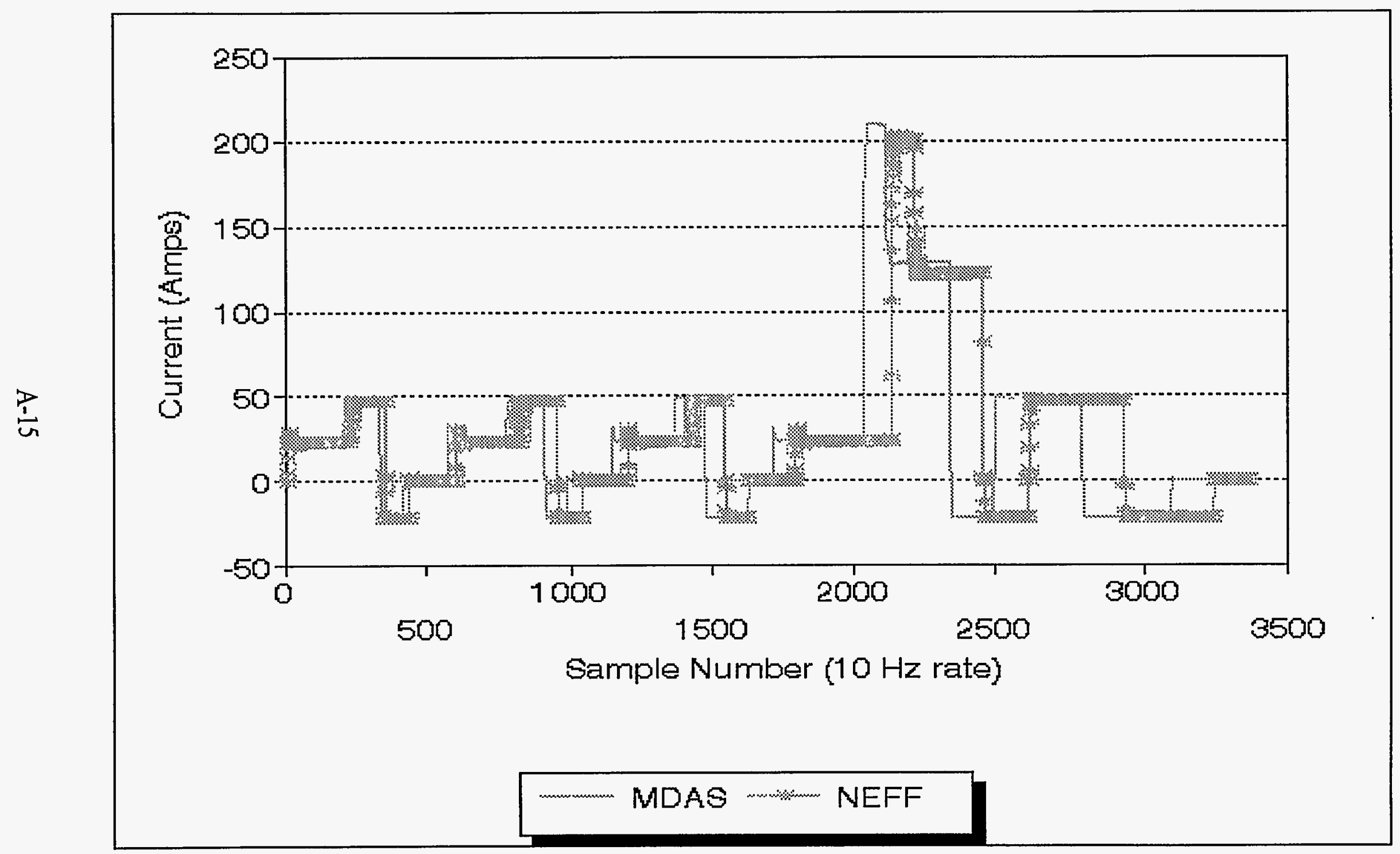

Figure 13. MDAS Test 11 [voltage] modified SFUDS at $0^{\circ} \mathrm{C}$. 


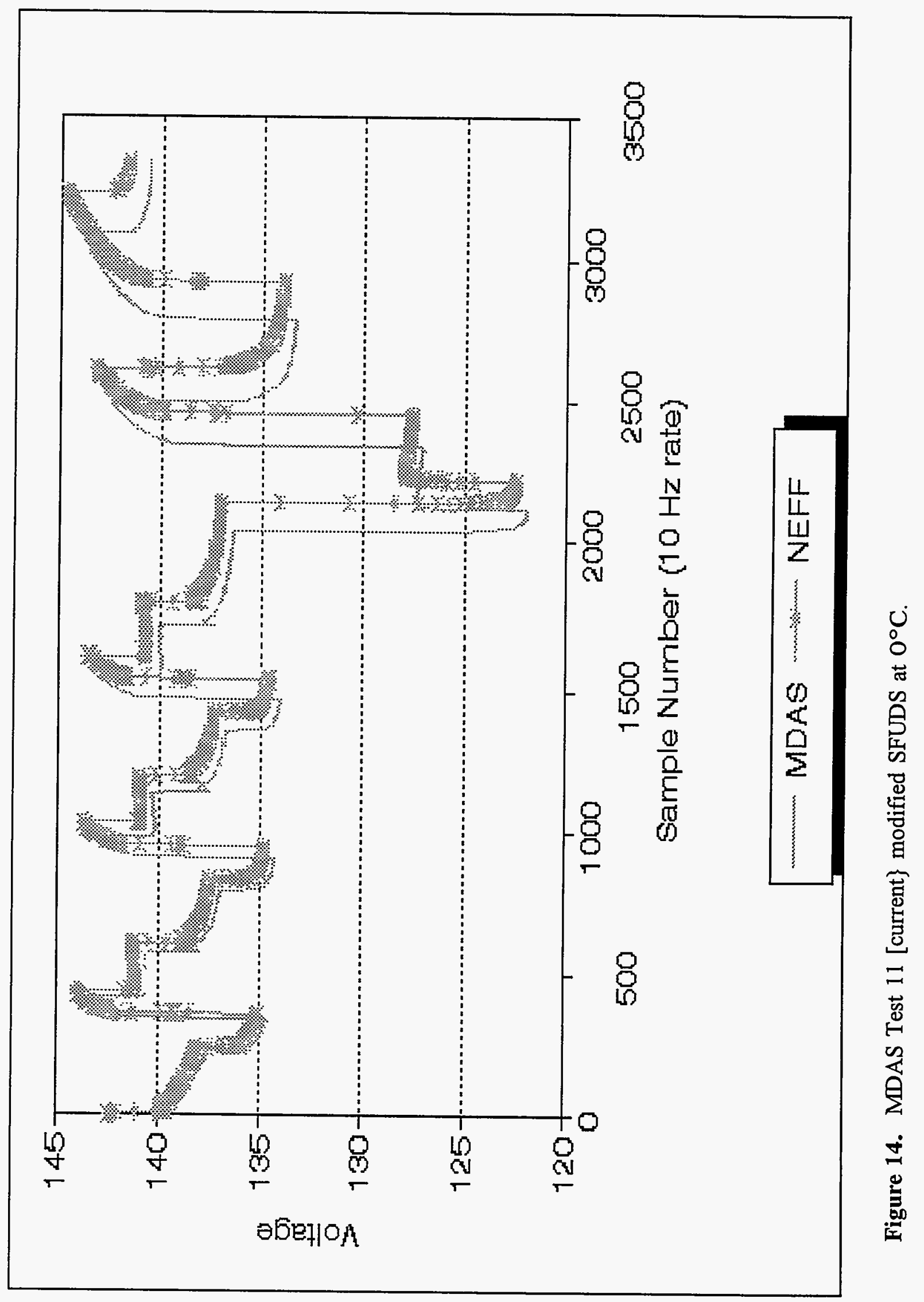




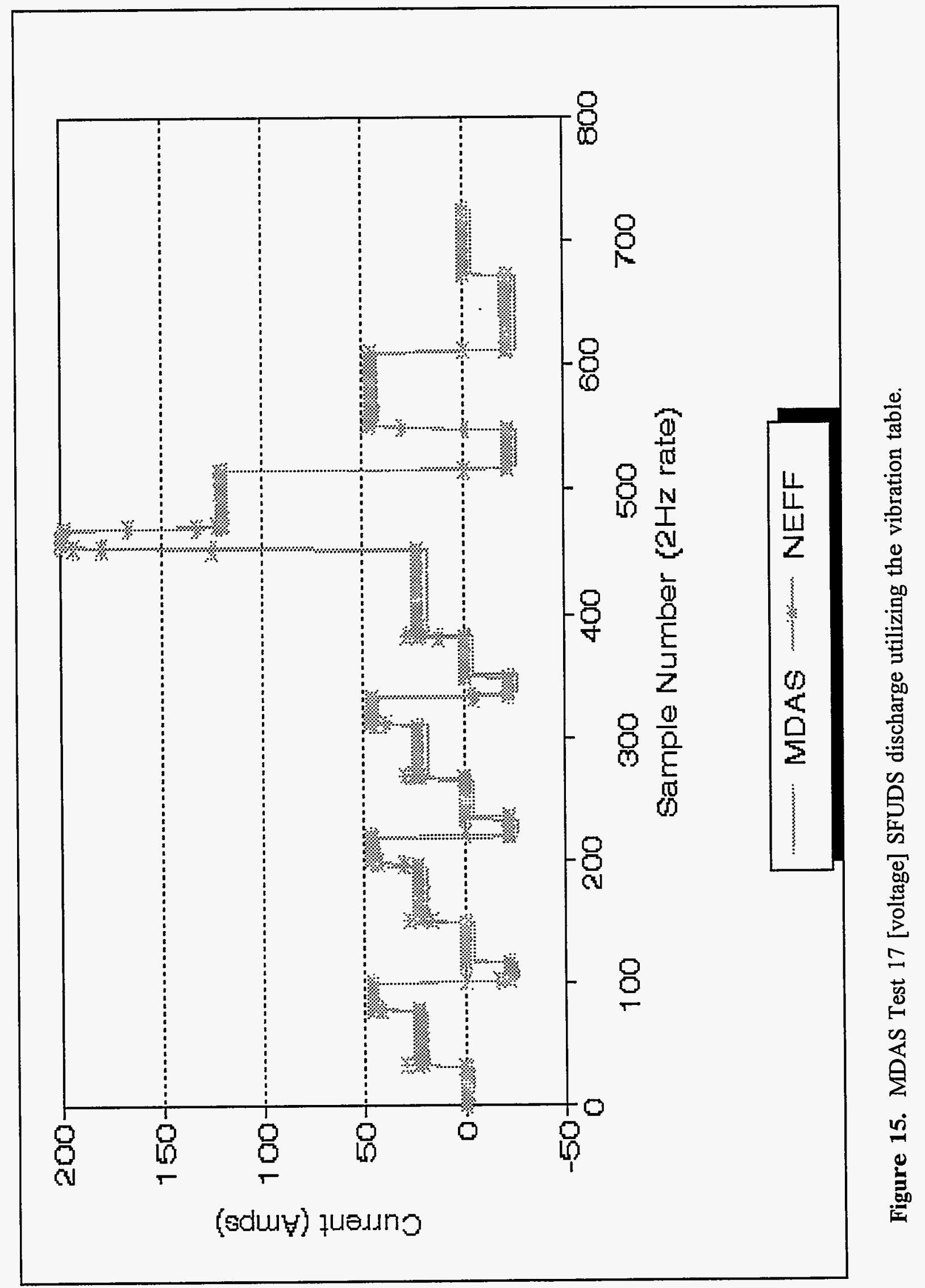




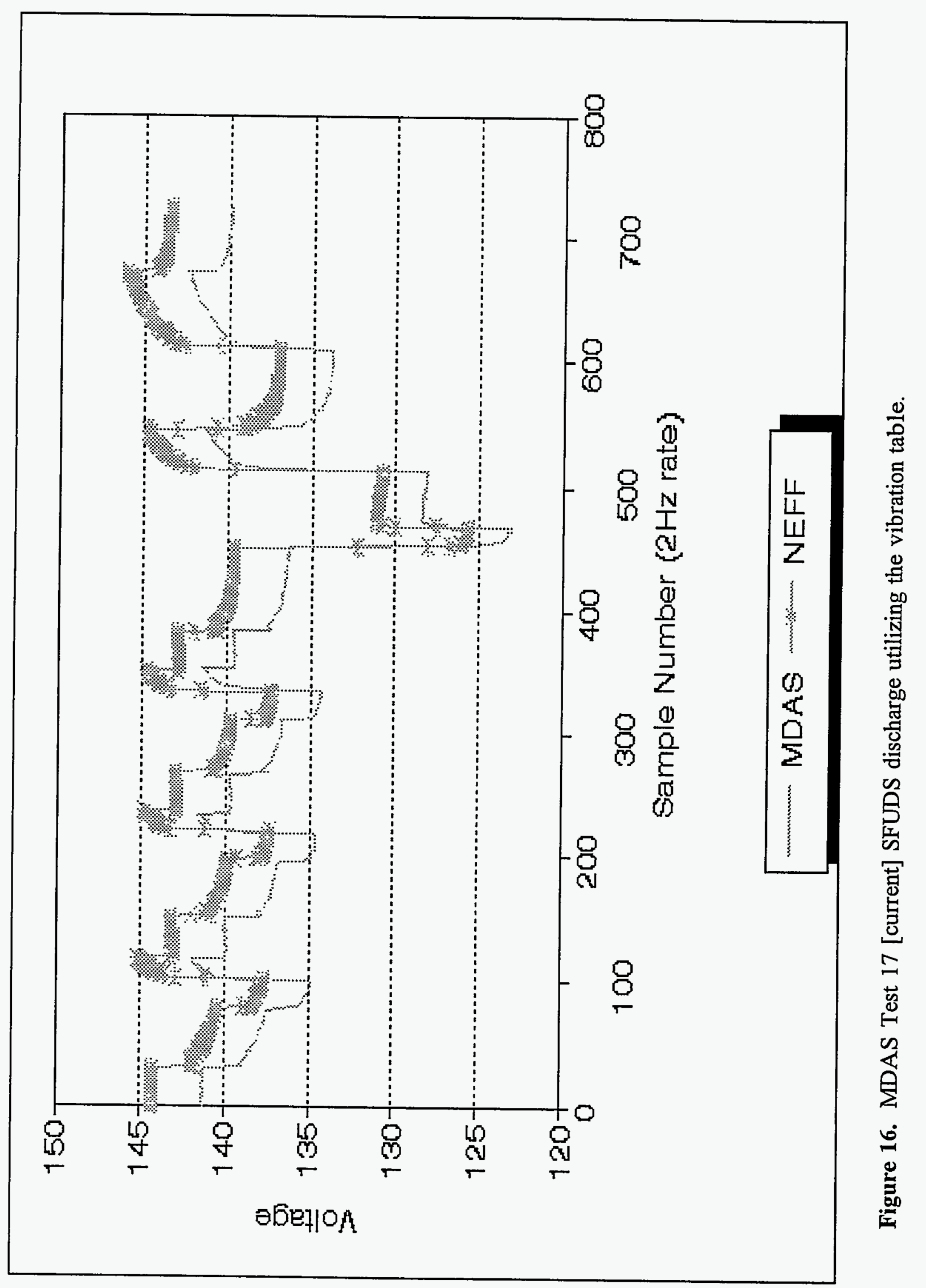


APPENDIX B

Detailed Description of the MDAS Specifications and Operation 
Sigma TecSystems, Inc.

$\mathrm{Tel} / \mathrm{Fax}$ 813-948-2372

MobiLe

DatA

Acquisition

SYSTEM

A complete system for the automatic collection.

transmission. analysis and presentation of performance

data for electric and alternative fuel vehicles.

FEATURES

ADVANTAGES

- Instant setup

- User friendly

- Battery Operated.

10 to 12 VDC

- Auto ON/OFF

- Watchdog alarm

- Potrer Failure Detector

- 16 Analog input channels

- Built-in Anti-Aliasing Circuitry

- 8 Digital Input Ports

- 8 Digital Output Ports

- Sensor input ready

- 2 Serial Ports

- Secure Disk Data Storage

- Up to 4 MBytes of RAM

- Compressed Binary Data

- 100\% IBM compatible
- Preconfigured. calibrated and tested.

- No special training or maintenance required.

- 30mA standby, 1.2A normal operation. 2A maximum current draw during disk $I / 0$.

- Self turn-on if $5 \mathrm{~V}$ to $12 \mathrm{~V}$ pulse sensed from any of 3 inputs or from telephone ring.

Softrare power-down after task completion.

- Audible alert on hardrare or softrare error.

- Automatic reset of CPU if power falls outside proper operational window.

- Accepts any $-10 \mathrm{~V}$ to $+10 \mathrm{~V}$ transducer input.

- Eliminates measurement errors due to noise on any analog input channel.

- Monitor the state of 8 separate devices.

- Control 8 separate devices via SCRs or relays.

- Built in $F / V$ converter to measure speed. Precision voltage reierence for thermistors.

- Serial interface for optional concurrent processors or $1 / 0$ devices.

- Reliable 1.44M floppy disk for portability.

- All data mritten to RAir until system is at rest.

- Secure encrypted data, compressed up to $90 \%$ from ASCII to minimize telemetry and media time and expense.

- Vast selection of IBM compatible softrare and hardware for custom applications and expansion.

\section{OPTIONS}

- Cellular Link

- Telephone Ring Detection

- Mini Console

- Data Presentation Softrare

\section{ADVANTAGES}

- Cellular phone softmare and hardware interface for automatic remote data retrieval.

- Use standard telephone lines, if conrenient, for data communications.

- Realtime feedback or instructions for operator or monitor. with keypad entry for special tasks.

- On-site analysis. graphics and hardcopy of user selected parameters. 
IHE SIGMA TECSYSTEMS MDAS: NOT JUST A DATA LOGGER!

The Sigma Tecsystems Mobile Data Acquisition System (MDAS) was specifically designed for applications in electric (EV) and alternative fuel vehicies. Gemeric data loggers (GDLS) are not particulariy suited for use in EVs but are best used for siowiy occurring events or short time spans. The following will explain some of the differences and show why the MDAS out performs GDIs in electric and alternative fuel vehicle installations.

\section{PEREORMANCE}

Sampling rates of up to $5000 \mathrm{~Hz}$ can be implemerted with MDAS. Although a sampling rate of 64 per second will exceed any present measurement requirements in an EV, the capabiuity to switch to a bigh sampling rate wider software control is somerimes used to more closely eramine specific EV phenomena.

SIZE

Overall outside dimensions of $3.25^{n} \times 6^{n} x$ $12^{\prime \prime}$ make the MDAS convenient to install in an EV and yet house a complete IBM compatible CPU, modem, power supply, $A / D$ card, Signal Conditioning card, and $1.44 \mathrm{Meg}$. floppy disk drive. The MDAS designers have sacriñced a litule extra size over the typical GDL for the unimited compatibiiity and expandability of the IBM platform.

\section{POFER CONSUTHETION}

No separate batteries are reguired by the MDAS since it derives power from the existing vebicle awriliary battery. To conserve power the MDAS shurs itself off when the EV is idle, then automatically powers up on several scimuli indicating EV activity or incoming telephone call.

\section{SENSIDTVTTY}

With 12 bit resolution on $16 \mathrm{~A} / \mathrm{D}$ chamels the MDAS is capable of accuracy of .005 . volts per input for a 20 volt input range. This accuracy excoeds that of any transducers currently used in EVs but ensures that the $A / D$ conversion process has the precision required for scientific research.

\section{SIGNAL CONDITUONING}

All imputs to the $M D A S A D D$ channels are fully conditioned by double pole active filters proviäing a $60 \mathrm{~dB}$ per decade attenuation of noise.

\section{SPEEDOMETER DNPUT}

On board circuirry allows the direct input of an EV speedometer signal for spead, acceleration and oistance measurements.

The typical GDL requires addirional circuitry to accomplish these measurements.

\section{THERMISTOR DNPUTS}

Four channels are provided for the direct connection of external thermistors. An on board precision voltage reference allows accurate temperature measurements of EV $c a b$, battery and ambient temperatures. A GDL would require additional circuitry for these measurements, while the $M D D A S$ comes with easy to install thermistors.

\section{STORAGE MEDTA}

It has been determined that daily measurements on EYS may require the storage of up to 200 kbytes of information. The MDAS can typically retain up to a full week of vehicle performance data, while the typical GDI cannot even hold one day's requirements! The MDAS saves considerable time and expense in data transferal and operator intervention. 